\title{
Epidemiological impact of recent influenza viruses in various countries
}

\author{
P. J. DELON \\ M.D. \\ F. ASSAAD* \\ M.D.
}

Epidemiological Surveillance of Communicable Diseases and *Virus Diseases, WHO, Geneva

\section{Summary}

During recent years, although influenza $B$ has given rise to epidemics every 3-5 years, influenza $A$ has caused greater concern to those responsible for the surveillance of the disease. The usual cycle of influenza A waves every 2 or 3 years was modified in many countries by the yearly appearance of new variants of the virus A/Hong Kong/68 (A/England/42/72, A/Port Chalmers/1/73). However, a number of countries, mostly located in Eastern Europe, were not attacked by virus $A$ infections in 1973-74, when the modified variant $A /$ Port Chalmers/1/73 caused a small wave in many areas of the world (this wave occurred in addition to, and often followed, a wave with virus B). Then, in 1974-75, the same countries of Eastern Europe were affected by an epidemic associated with viruses related to A/Port Chalmers, which was generally more widespread in these countries than in those already attacked by this variant the previous year. The epidemiological circumstances which may have led to such differences are not clear, all the more so as these differences were found even in neighbouring countries.

Moreover, the antigenic drift which led from $\mathrm{A} /$ England/72 to A/Port Chalmers/73 was of the same magnitude as the previous one which led from $A / H o n g$ Kong/68 to $A /$ England/72, but the wave of $A /$ England was much sharper than that of A/Port Chalmers. Also, during the epidemics with $\mathrm{A} / \mathrm{Hong} \mathrm{Kong} / 68$ of influenza year 1971-72, the variant A/Hong Kong/107/ 71 became fairly widespread. In haemagglutination inhibition tests, $\mathrm{A} / \mathrm{Hong} \mathrm{Kong} / 107 / 71$ was much more remote from $A / H o n g ~ K o n g / 68$ than was the subsequent variant $A /$ England/42/72. In spite of this, $A /$ England/ 42/72 caused vast epidemics the following year whilst A/Hong Kong/71 disappeared.

Although antigenic drifts constitute an element of prediction for patterns of spread of influenza, they are only one of the determining factors which govern the propagation of the viruses. There is at present no clear explanation for the differences in epidemic potential between influenza viruses (as well as for differences in clinical virulence). There is a need for a continuing study of the parameters governing the differences in spread between countries. For this purpose, health administrations should develop further the use of epidemiological indices, the significance of which should be carefully assessed.
Introduction

The epidemiological impact of influenza viruses depends on many factors, but above all on the antigenic changes of the virus and the previous exposure of populations. As a result, although variations between countries are often observed during the same epidemic season, each year shows an influenza pattern common to most countries. The purpose of this paper is to outline briefly the story of the epidemic waves which, since the pandemic of 1957 (virus A 'Asiatic'), were associated with virus $A$ or virus $B$, with particular emphasis on the impact of infections with virus A from October, 1974 to March, 1975.

Materials and methods

The network of ninety-six national centres in sixtynine countries and the two WHO Collaborating Centres for Reference and Research on Influenza in London and Atlanta, is the basis of the WHO Influenza Surveillance Programme, which started in 1947. The national centres send each week to WHO, Geneva, epidemiological reports supported by their preliminary laboratory findings, using the WHO special reporting forms. The collaborating centres in London and Atlanta identify the influenza strains they receive from the national centres and inform WHO of the results. These two categories of information are consolidated and published in the $\mathrm{WHO}$ Weekly Epidemiological Record. This process has made it possible to follow the evolution of influenza viruses $\mathrm{A}$ and $\mathrm{B}$ and to have an idea of their annual epidemiological impact in various countries throughout the world, especially when these countries use epidemiological indices (WHO Weekly Epidemiological Records, 1971) which enable comparisons to be made between data obtained over successive years. Among these indices, three types have mostly been used:

Mortality from influenza, e.g. U.K. (Miller and Lee, 1967); excess mortality from pneumonia and influenza, e.g. U.S.A. (Langmuir and Housworth, 1969); or from respiratory diseases, e.g. WHO Collaborative Study including fourteen countries (Assaad, Cockburn and Sundaresan, 1973).

Reporting of cases by voluntary notification, e.g. practices reporting to the Royal College of General Practitioners in the U.K. (Miller and Lee, 1967); 
sentinel stations in The Netherlands; or compulsory notification, e.g. notification by public health officers in Hungary, Czechoslovakia and Sweden, and by private practitioners in Switzerland.

Absenteeism from work, e.g. claims to sickness benefit in the U.K. (Miller and Lee, 1967) and Sweden.

\section{Results}

(a) Evolution since 1957 (WHO Weekly Epidemiological Records, 1957-64, 1965, 1966, 1967, 1969, 1970, 1971, 1972, 1973, 1974, 1975)

Contrary to sub-type A/Singapore/1/57 $\left(\mathrm{H}_{2} \mathrm{~N}_{2}\right)$ prevalent from 1957 to 1968 , which showed only two significant antigenic drifts in 1964 and 1967, subtype $\mathrm{A} / \mathrm{Hong} \mathrm{Kong} / 1 / 68\left(\mathrm{H}_{3} \mathrm{~N}_{2}\right)$, prevalent since 1968 (Cockburn, Delon and Ferreira, 1969), has generated new variants each year since 1971. From 1957 to 1972, epidemic waves associated with virus A occurred every 2 or 3 years, with the exception of the period 1967-1970 when three epidemics were observed in three consecutive years. The last two followed the appearance of sub-type A/Hong Kong/1/ 68. However, since the spread of the variant $\mathrm{A} /$ England/42/72 in 1972-73, a new epidemiological pattern was observed, the yearly antigenic drifts being associated with the yearly appearance in most countries of epidemic waves generally of low or moderate importance. In 1973-74 and 1974-75, these drifts generated the appearance in various places of several variants (WHO Weekly Epidemiological Records, 1975) differing more or less one from the other, with variable epidemiological impacts. The principal ones were A/Port Chalmers/1/73 (Schild et al., 1974) and A/Scotland/840/74.

Virus B has caused epidemics every 3-5 years since 1958. Their attack rates (low or moderate) never reached the level of those observed during pandemics associated with virus $A$. The variants of virus B which spread in the world causing one or more of these periodic waves, appeared in 1958, 1967 and 1972. The last one, B/Hong Kong/5/72, and various strains B 'intermediate' between this variant and the previous one, were associated in most countries with an epidemic wave during the winter 1973-74 (during which an additional wave associated with virus $\mathbf{A}$ occurred in many countries). At the same time, strains close to B/Victoria/98926/70 (similar to the variant of 1967) continued to circulate in parallel with the new strains. This persistence of old $B$ variants along with the new ones was observed several times since 1958.

\section{(b) Impact of influenza infection during the period} October, 1974-March, 1975

Although of great value for WHO records, the determination of the epidemiological impact is often inaccurate when it is based only on narrative descriptions unsupported by figures. In general, $\bar{a}$ national attack rate is qualified as 'low' for sporadie cases or local outbreaks, 'moderate' when the epis. demic level is reached in the general population of $\vec{a}$ : large part of the country, and 'high' when severef epidemics occur such as those of 1969-70 in Europe? following the spread of virus A/Hong Kong/1/68 $\frac{\bar{C}}{\bar{W}}$. Epidemiological indices, when they are used, enable health administrations and WHO to appreciate ob jectively the extent of the problem.

क

Study of data obtained from epidemiological indices 5 in some countries. Figure 1 and Tables 1 and 2 below; show data obtained from various indices in various countries during the last two epidemic waves asso $\frac{\text { o }}{8}$ ciated with virus $A$, in relation to the corresponding data from the moderate epidemic of 1972-73 asso?. ciated with the spread of virus A/England/42/72 and the major epidemic which followed the appearanco of virus A/Hong Kong/1/68 (1968-69 in the U.S.A.9 1969-70 in other countries). In the U.S.A., the majort attack by the $A /$ Hong Kong/68 virus occurred in 1968-69, whilst its impact in 1969-70 was onlymoderate. The reverse happened in most countries of Europe where the major attack by this sub-type occurred in 1969-70, whilst its impact in 1968-69 was small or moderate. The Netherlands and Poland conn- $\overrightarrow{0}$ stituted two exceptions as they experienced two cen secutive large epidemics associated with A/Hong Kong/68 in 1968-69 and 1969-70.

It appears that in those of the above countries which had been attacked by infections with virus $A$. in 1973-74 (U.S.A., U.K., Sweden), the wave of 1974-75 was fairly small. On the other hand, of the above countries which were not attacked by infec-0을 tions with virus A in 1973-74, Hungary experienced 3 a large epidemic in 1975, and moderate epidemics? occurred in the Czech provinces of Czechoslovakia? as well as the northern and eastern provinces of ${ }_{3}^{\circ}$ The Netherlands; Switzerland and the rest of The Netherlands were only slightly affected.

Global study of the worldwide impact. During the influenza season which ended in March, 1975, a total $\frac{\text { ? }}{3}$ of thirty-six countries in Africa, America, Asia and Europe notified influenza infections to WHO. Most ? of them reported local outbreaks and an increased $\frac{D}{O}$ incidence of sporadic cases. This was the case in the U.S.A., Canada, most countries of Western Europe, $\mathbb{N}$ Scandinavia, Tunisia, Israel and Japan. However, N influenza caused large epidemics in Poland $(4,900,000 \mathrm{~N}$ cases, i.e. an attack rate of $14.6 \%$ ), in the western ${ }_{\sigma}^{\omega}$ region of Hungary and in Morocco, and moderate epidemics in the general populations of the eastern ${ }^{\circ}$ region of Hungary, Bulgaria, and Czech provinceses of Czechoslovakia, U.S.S.R., German Democratic Republic, the northern and eastern provinces of The Netherlands, and some areas of Scotland (e.g. Dun-需 dee); in Scotland, the new A/Scotland/840/75 variant 

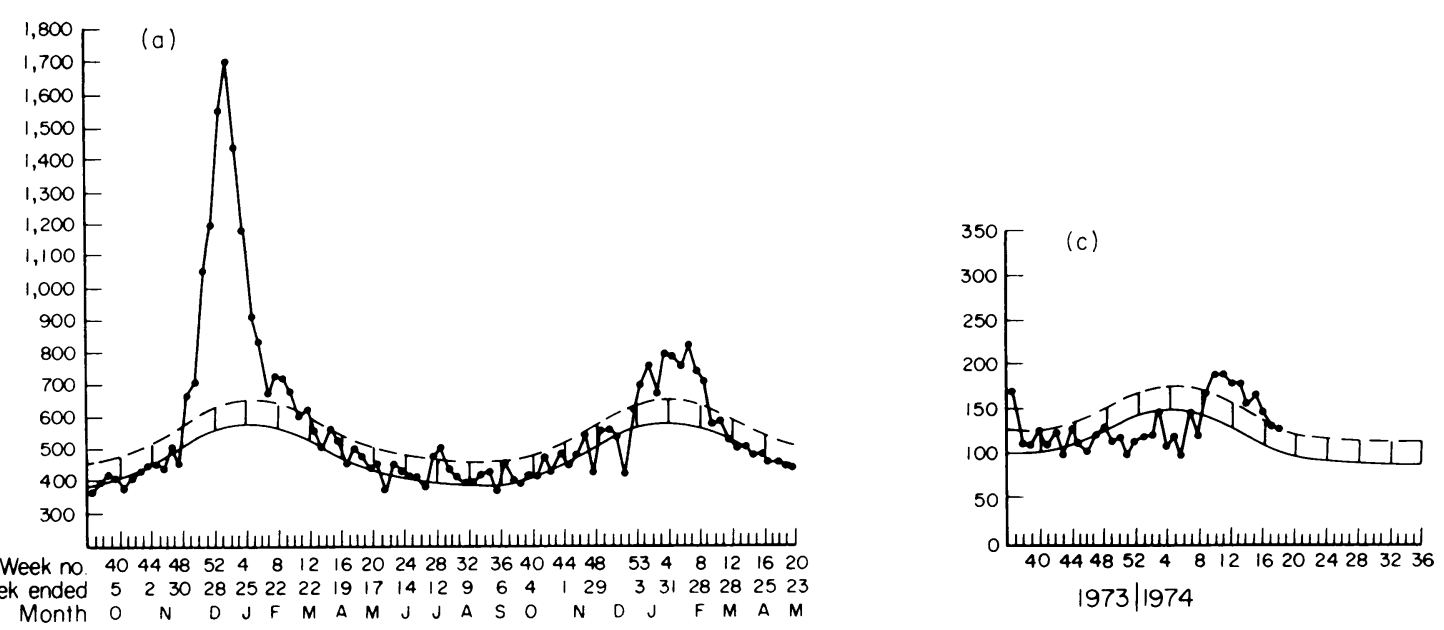

1968/1969 1969/1970

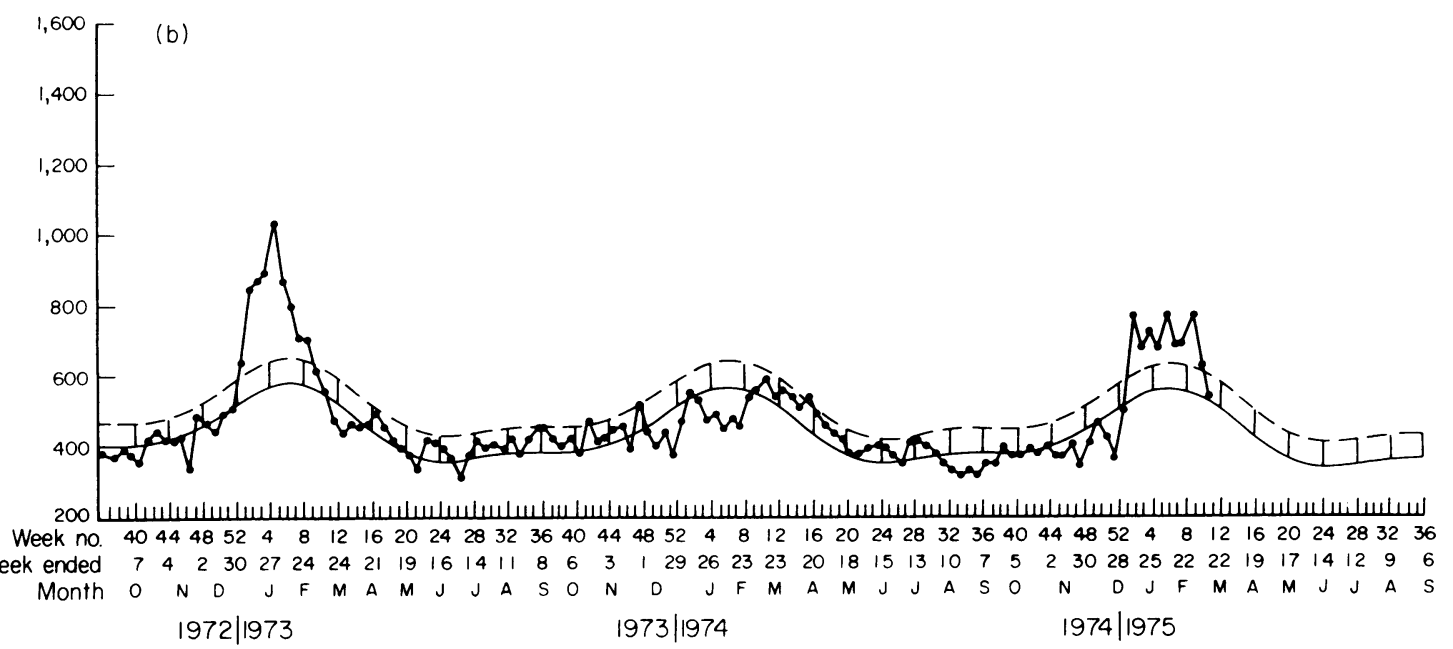

FIG. 1. Pneumonia-influenza deaths in (a) 122 United States cities, (b) 121 United States cities and (c) Middle Atlantic Division (20 cities). - . - Epidemic threshold; - expected number. The Middle Atlantic Division was the only one to show a significant excess mortality from pneumonia and influenza in 1973-74.

TABLE 1. Comparison of the maxima of three epidemiological indices during recent influenza $A$ outbreaks in England and Wales

\begin{tabular}{lcccc}
\hline \multicolumn{1}{c}{ Maximum weekly figures for } & \multicolumn{4}{c}{ Influenza season } \\
\cline { 2 - 5 } & $1969-70$ & $1972-73$ & $1973-74$ & $1974-75$ \\
\hline $\begin{array}{l}\text { Influenza deaths } \\
\text { Influenza cases reported to Royal }\end{array}$ & 3170 & 882 & 109 & $135^{*}$ \\
$\begin{array}{l}\text { College of General Practitioners } \\
\text { (per 100,000) }\end{array}$ & $918 \cdot 1$ & $520 \cdot 3$ & $120 \cdot 9$ & $136 \cdot 6 \dagger$ \\
$\begin{array}{l}\text { New claims to sickness benefit } \\
\text { (absence from work) }\end{array}$ & 752,517 & 419,233 & 250,391 & $223,600 \ddagger$ \\
\hline
\end{tabular}

* Expected number for the same week in non-epidemic years: 49 .

$\dagger$ Expected incidence for the same week in non-epidemic years: $69 \cdot 2 / 100,000$.

$\ddagger$ Expected number for the same week in non-epidemic years: 207,700 . 
TABle 2. Some figures extracted from the morbidity data reported by some European countries during recent influenza A outbreaks*

\begin{tabular}{|c|c|c|c|c|}
\hline & \multicolumn{4}{|c|}{ Influenza season } \\
\hline & $1969-70$ & $1972-73$ & $1973-74$ & $1974-75$ \\
\hline $\begin{array}{l}\text { Hungary-total number of notified } \\
\text { influenza cases for the epidemic }\end{array}$ & $2,200,000$ & $1,130,000$ & (virus B) $\dagger$ & $1,400,000$ \\
\hline $\begin{array}{l}\text { Czechoslovakia-maximum weekly } \\
\text { incidence of notified acute } \\
\text { respiratory diseases in Czech } \\
\text { provinces (per } 100,000 \text { ) }\end{array}$ & 4700 & 2500 & (virus B) & 2500 \\
\hline $\begin{array}{l}\text { The Netherlands-maximum weekly } \\
\text { incidence of influenza cases } \\
\text { notified by sentinel stations }\end{array}$ & $\begin{array}{c}\text { Not } \\
\text { available }\end{array}$ & 115 & (virus B) $\ddagger$ & $89 \S$ \\
\hline $\begin{array}{l}\text { Switzerland-maximum weekly } \\
\text { number of notified influenza cases }\end{array}$ & 11,358 & 5265 & (virus $\mathrm{B}) \#$ & 2967 \\
\hline $\begin{array}{l}\text { Sweden-maximum weekly number } \\
\text { of influenza cases reported by } \\
\text { PH officers }\end{array}$ & 40,300 & $\begin{array}{l}\text { Not } \\
\text { available** }\end{array}$ & 10,246 & 15,254 \\
\hline
\end{tabular}

* This table simply illustrates the kind of data made available to WHO and in no way should be used for international comparison.

$\uparrow 501,000$ cases.

$\ddagger$ Maximum weekly incidence: 78 per 10,000 .

$\S$ The incidence in the two provincial groups including the northern and eastern provinces was twice as high as in the two provincial groups including the western, central and southern provinces.

\# Maximum weekly number: 509.

** Cases throughout the country, but incidence reported to be low.

was prevalent. In tropical countries, moderate epidemics occurred in Kenya, Central African Republic and Trinidad and Tobago, whilst a small epidemic wave occurred in Malaysia.

\section{Discussion and conclusion}

The above data show that, during recent years, the usual cycle of influenza A waves every 2 or 3 years was modified in many countries by the yearly appearance of new variants of the virus $A / H o n g$ Kong/68. An epidemic with virus $A /$ England/42/72, moderately widespread in general, occurred in 1972-73-1 year after an epidemic associated mostly with the initial A/Hong Kong/68 virus. This epidemic with A/England/42/72 was also observed in Eastern European countries which had been severely affected by the wave of the previous year. However, most countries of Eastern Europe, with the exception of the German Democratic Republic and the U.S.S.R., were not attacked by virus $A$ infections in 1973-74, when the modified variant $A /$ Port Chalmers/1/73 caused a small wave in many areas of the world (often towards the end of the season). Then, in 1974-75, the same countries of Eastern Europe were affected by an epidemic associated with viruses related to A/Port Chalmers, which was generally more widespread in these countries than in those already attacked by this variant the previous year. Therefore, since the spread of the variant A/Port Chalmers in
1973-74, two main epidemiological patterns hâेeo apparently co-existed. Many countries experienced two small influenza A waves in two consecutive years, whilst others had 1 year free from influenza $A$ infec- $\frac{0}{D}$ tions with a larger influenza $A$ wave during the sub- $\cong$ sequent year. The epidemiological circumstancess $\overrightarrow{\vec{O}}$ which may have led to such differences are not clear,, all the more so as these differences were found even in neighbouring countries. For instance, The Nether-? lands was not attacked during the winter of 1974 by을 influenza A outbreaks, whereas the Federal Republic. of Germany was.

Other epidemiological observations give cause for thought. As measured by haemagglutination inhibition tests, the antigenic drift which led from $\mathrm{A} / 0$ England/72 to A/Port Chalmers/73 was of the same magnitude as the previous one which led from $A / D$ Hong Kong/68 to A/England/72, and both A/Port Chalmers and $\mathrm{A} /$ England became widespread. How- No ever, for reasons unknown, the wave of A/England was much sharper than that of A/Port Chalmers. N Also, during the epidemics with A/Hong Kong/68 of $\omega$ influenza year 1971-72, the variant A/Hong Kong $/ 2$ $107 / 71$ became fairly widespread; it was often isolated in Asian countries and sometimes in European countries. In haemagglutination inhibition tests, $\mathrm{A} / \stackrel{?}{+}$ Hong Kong/107/71 was much more remote from $\frac{}{-}$ A/Hong Kong/68 than was the subsequent variant $\frac{}{\mathbb{D}}$ A/England/42/72. In spite of this, A/England/42/72 
caused vast epidemics the following year whilst A/Hong Kong/71 disappeared.

Although antigenic drifts constitute an element of prediction for patterns of spread of influenza, they are only one of the determining factors which govern the propagation of the viruses. There is at present no clear explanation for the differences in epidemic potential between influenza viruses (as well as for differences in clinical virulence). Moreover, there is a need for a continuing study of the parameters governing the differences in spread between countries. Among these parameters, the previous exposure of populations, their density and their movements, and the climatic conditions (Davey and Reid, 1972) are of special importance. In particular, the influence of the climate on the influenza seasons' in tropical countries should be investigated. In any case, only a broader use by health administrations of carefully assessed epidemiological indices will make it possible to implement valid epidemiological studies based on reliable measurements. Research on these indices should be further developed.

\section{References}

AssaAd, F., Cockburn, W. \& Sundaresan, T.K. (1973) Use of excess mortality from respiratory diseases in the study of influenza. Bulletin of the World Health Organization, 49, 219.
Cockburn, W., Delon, P.J. \& Ferreira, W. (1969) Origin and progress of the 1968-69 Hong Kong influenza epidemic. Bulletin of the World Health Organization, 41, 345.

DAVEY, M.L. \& REID, D. (1972) Relationship of air temperature to outbreaks of influenza. British Journal of Preventive and Social Medicine, 26, 28.

LANGMUIR, A.D. \& HousworTh, J.A. (1969) A critical evaluation of influenza surveillance. Bulletin of the World Health Organization, 41, 393.

Miller, D.L. \& LeE, J.A. (1967) Influenza in Britain 19671968. Journal of Hygiene, 67, 559.

Schild, G.C., OXford, J.S., Dowdle, W.R., Coleman, M., Pereira, M.S. \& Chakraverty, P. (1974) Antigenic variation in current influenza $A$ viruses: evidence for a high frequency of antigenic 'drift' for the Hong Kong virus. Bulletin of the World Health Organization, 51, 1.

WHO (1971) Technical guide for a system of influenza surveillance. Weekly Epidemiological Records, 46, No. 8.

WHO (1975) Recommended composition of influenza vaccines for use in the 1975-76 season. Weekly Epidemiological Record, 50, No. 14.

WHO (1957 to 1964) Weekly Epidemiological Record, volumes 33 to 39 .

WHO (1965) Weekly Epidemiological Record, 40, No. 30.

WHO (1966) Weekly Epidemiological Record, 41, No. 51/52.

WHO (1967) Weekly Epidemiological Record, 42, No. 49.

WHO (1969) Weekly Epidemiological Record, 44, No. 1.

WHO (1970) Weekly Epidemiological Record, 45, No. 15 and 39.

WHO (1971) Weekly Epidemiological Record, 46, No. 34 and 50.

WHO (1972) Weekly Epidemiological Record, 47, No. 45. WHO (1973) Weekly Epidemiological Record, 48, No. 48. WHO (1974) Weekly Epidemiological Record, 49, No. 34. WHO (1975) Weekly Epidemiological Record, 50, No. 4. 